\title{
Expectancy and stimulus frequency: A comparative analysis in rats and humans
}

\author{
KEVIN PANG, FRED MERKEL, HOWARD EGETH, and DAVID S. OLTON \\ The Johns Hopkins University, Baltimore, Maryland
}

\begin{abstract}
We examined whether expectancy, one of several factors influencing attention, is similarly affected in rats and humans by manipulation of relative stimulus frequency. A two-choice reaction time (RT) task was developed for rats, and an analogous task was used for humans. Errors, RTs, discriminability, and response bias were measured. Both rats and humans shifted their response bias to the more frequent stimulus, with no change in overall discriminability. As stimulus probability or stimulus repetition increased, RTs and errors decreased. These results illustrate the similarity of expectancy in rats and humans. This two-choice RT task for rats can be used in future studies to examine the neuronal mechanisms of expectancy and attention.
\end{abstract}

Attention enables individuals to deal effectively with the tremendous amount of information that they encounter. Knowledge of the cognitive mechanisms of attention is, therefore, important for theories of information processing. Research with human subjects has led to many psychological theories of attention (for reviews, see, e.g., Broadbent, 1958; Deutsch \& Deutsch, 1963; Egeth, 1967; Posner, 1986).

The neurobiological mechanisms of attention have been studied in humans using event-related brain potentials (Donchin, Karis, Bashore, Coles, \& Gratton, 1986; Hillyard \& Kutas, 1983), positron emission tomography (Corbetta, Miezin, Dobmeyer, Shulman, \& Petersen, 1990), and neuropsychological analysis of brain-damaged patients (Posner, Walker, Friedrich, \& Rafal, 1984). However, investigations of the cellular mechanisms of attention (single cells, neurotransmitter systems, etc.) still require the use of animal models to obtain more direct access to the brain than is possible in humans. To assess the appropriateness of a model, animal and human studies should be directly comparable. This comparison is facilitated by manipulating the same independent variables and measuring the same dependent variables for both humans and animals.

Attention can be influenced by expectancy. For example, attention may be shifted to the expected location of the target when a cue that predicts the location is shown

This research was supported by the Air Force Office of Scientific Research Grant AFOSR-89-0481 and the U.S. Public Health Service Research Grant NS08358. J. Toby Mordkoff made significant intellectual contributions to this work. Steven Yantis, Linda Gorman, Neil Macmillan, Harold Pashler, Donald Blough, Warren Meck, Bennet Givens, Alicja Markowska, Lester Krueger, and 3 anonymous reviewers provided helpful comments on earlier versions of this manuscript. Susan Knipp and numerous undergraduate students contributed their technical assistance throughout the study. Correspondence concerning this article should be addressed to K. Pang. Psychology Department, The Johns Hopkins University, 34th \& Charles Sts., Baltimore, MD 21218. to a subject (Posner, 1980). Expectancy is influenced by stimulus frequency, response frequency, stimulus repetition, and response repetition (Bertelson, 1961; Bertelson, 1965; Duncan-Johnson \& Donchin, 1982; Hick, 1952; Hyman, 1953; LaBerge \& Tweedy, 1964; Landauer, 1964; Niemi \& Naatanen, 1981; Rabbitt, 1959; Smith, 1968). A frequent stimulus is responded to faster than is an infrequent stimulus. Hypotheses emphasizing perceptual mechanisms propose that attention is directed to the more frequent stimulus, resulting in more effective encoding or identification of this stimulus (Biederman \& Zachary, 1970; Blackman, 1972; Hawkins \& Friedin, 1972; Hawkins \& Hosking, 1969; Miller \& Pachella, 1973). A frequent response is faster than is an infrequent one (Bertelson, 1965). Hypotheses emphasizing response mechanisms propose that subjects are more likely to select frequent responses than infrequent ones (Biederman \& Stacy, 1974; Dillon, 1966; Sanders, 1970; Theios, 1973, 1975). The frequency of stimuli and responses can jointly influence expectancy, and the relative contribution of each may depend on task parameters (Duncan-Johnson \& Donchin, 1982; Hinrichs \& Krainz, 1970; LaBerge \& Tweedy, 1964; Miller \& Pachella, 1976; Pachella \& Miller, 1976). The present study manipulated stimulus and response frequencies concurrently, and was not directed at dissociating the effect of stimulus frequency from that of response frequency. For simplicity, the paper hereafter refers to both stimulus and response frequencies as stimulus frequency.

A frequent stimulus is more likely to be repeated on consecutive trials than is an infrequent stimulus. Because of this correlation, the relative frequency of a stimulus in a test session (general session effect of stimulus frequency) may influence mean reaction time (RT) and accuracy by altering the probability of a stimulus (stimulus probability effect) or by altering the number of sequential repetitions of a stimulus (stimulus repetition effect). Note that we use the term "stimulus probability effect" to refer to the specific effects of stimulus probability when 
repetition is held constant, not to the overall effect of stimulus frequency.

Stimulus repetitton can improve performance independent of stimulus probability (Bertelson, 1965; Kornblum, 1973), and such improvements may be due to an enhancement of stimulus identification (Hinrichs \& Krainz, 1970; Smith, 1968). The repetition of responses (response repetition) on sequential trials can also improve performance, possibly due to benefits in response execution and response selection (Rabbitt, 1959). In combination, stimulus and response repetitions often produce larger improvements in performance than does stimulus or response repetition alone (Ells \& Gotts, 1971; Smith, 1968).

The effects of expectancy and attention may also depend on the stimulus modality. In humans, auditory stimuli may capture attention directed at stimuli in another modality (Posner, Nissen, \& Klein, 1976). The same may be true for rats because an auditory stimulus can immediately capture attention from a visual stimulus (Meck, 1984). Thus, attention in both humans and rats may be more readily captured by auditory stimuli than by visual stimuli.

In the present study, we examined expectancy in rats and humans using directly comparable procedures. Choice RT tasks were performed by rats and humans, and expectancy was manipulated by varying the relative frequencies of two stimuli. We addressed three issues: (1) Does stimulus frequency influence expectancy in rats and humans in similar ways? (2) Does stimulus frequency affect expectancy for auditory stimuli, as well as that for visual stimuli? If so, are the effects of stimulus frequency similar for the two modalities? (3) What are the relative contributions of the probability effect and the repetition effect in expectancy? The comparable data we obtained for rats and humans provide evidence that the behavioral procedure described here can be used to examine the neurobiological substrates of expectancy and attention.

\section{EXPERIMENT 1: RATS}

Studies of expectancy and attention in humans have traditionally measured RT and accuracy as a function of the number and/or relative frequency of stimuli and responses. To be directly comparable, studies of similar phenomena in rats should do likewise. The present experiment used a procedure that allowed rats to place one forepaw on each of two levers; this permitted two independent responses, one from each paw. A choice RT task was used to examine the effects of stimulus frequency on expectancy in rats. This task incorporated procedures that were similar to those used to examine expectancy and attention in humans.

\section{Method}

\section{Subjects}

Six naive, male Long-Evans rats ( 3 months old) began the experiment with body weights ranging from 250 to $350 \mathrm{~g}$. The animal colony room had a temperature of $20^{\circ}-21^{\circ} \mathrm{C}$ and a 12:12-h light:dark cycle, with lights on at $0700 \mathrm{~h}$. Each rat was allowed ad-lib food. At the start of training, water was restricted until the body weight was $85 \%$ of the unrestricted weight. Subsequently, sufficient water was given in the home cage during the last 2 hours of the light phase to maintain this weight. Each rat received one training session per day during the light phase.

\section{Apparatus}

The design of the operant boxes encouraged the rats to stand on their hind legs, use their forepaws to depress two levers simultaneously, and place their mouths near a waterspout. Visual and auditory stimuli, levers, and waterspout were positioned so that the stimuli were clearly discernible to the rat, and water could be collected with minimal movement.

Each operant box was constructed of clear Lucite with the following dimensions: $30 \times 27 \times 30 \mathrm{~cm}$ (height $\times$ width $\times$ depth). Two stainless steel levers ( $1.5 \mathrm{~cm}$ wide; BRS/LVE, Inc., Type SRL003) protruded $2.3 \mathrm{~cm}$ from the front panel; these levers were located $1 \mathrm{~cm}$ apart, $13 \mathrm{~cm}$ from the side walls and $12 \mathrm{~cm}$ above the floor of the box. A waterspout (18-ga stainless steel tube) was on the front panel, midway between the side walls and $4 \mathrm{~cm}$ above the levers. The visual stimulus, a Sylvania miniature lamp (Type 1819) with a clear lamp cover, was on the front panel, midway between the side walls and $10 \mathrm{~cm}$ above the waterspout. The auditory stimulus (Mallory Inc., Sonalert, Type SC628, $2900 \mathrm{~Hz}, 77 \mathrm{~dB}$ ) was generated by a speaker $10 \mathrm{~cm}$ above the waterspout and $6 \mathrm{~cm}$ to the right of the visual stimulus.

A sound-attenuating chamber (BRS/LVE, Inc.), $64 \times 102 \times$ $46 \mathrm{~cm}$ (height $\times$ width $\times$ depth), enclosed the operant box. A oneway mirror on one side of the chamber permitted observation of the rat during the task. A buzzer and houselight were within the sound-attenuating chamber, but outside the operant box. The buzzer (Edwards Inc., Lungen Buzzer, Type 15-2G1, $78 \mathrm{~dB}$ in operant box) was near the front panel of the operant box; the houselight (Sylvania miniature lamp, Type 1819), with a frosted white lamp cover, was near the back of the operant box.

An IBM PC computer and interface system (Med Associates, Inc.) controlled the experiment and recorded the data. A 28-V homemade dc power supply provided current for the stimuli in the operant box. A millisecond timer contained within the Med Associates interface measured RT.

\section{Training}

Each rat was taught to start a trial by simultaneously pressing two levers and to respond to each stimulus by releasing one of two levers. Each training session had 200-400 trials, in which $10-15 \mathrm{ml}$ of water was delivered to the rat; this was generally enough to maintain or increase the rat's body weight.

During Day 1, water reinforcement was paired with a leverpress. A small amount of water $(0.01 \mathrm{ml})$ was delivered when the rat explored near the waterspout or pressed a lever. Response bias was minimized by terminating the reinforcement of any lever that was pressed 25 times more than the other lever. When the number of leverpresses for both levers was equal, reinforcement for both levers resumed.

During Days 2 and 3, the release of either lever was reinforced if the release was preceded by the simultaneous pressing of both levers. Response bias was minimized as described above.

During Day 4, discrimination training was started. Each trial began when the rat simultaneously pressed both levers. One of the two stimuli was presented $0.5 \mathrm{sec}$ following the start of the trial. A correct response was a release of the left lever for a visual stimulus (light trials) or a release of the right lever for an auditory stimulus (tone trials). Following a correct response, the stimulus was turned off and water reinforcement was delivered. An incorrect re sponse was a release of the right lever on light trials or a release of the left lever on tone trials. Following an incorrect response, the stimulus was turned off, the buzzer was activated for $1 \mathrm{sec}$, and a 10-sec time-out period ensued, during which the houselight 
was turned off and no trials could be initiated. At the end of the time-out period, the houselight was turned on and the rat was allowed to start the next trial. If the rat released both levers in response to a stimulus, the first lever release, but not the second, was recorded as correct or incorrect. A premature response was a release of any lever prior to stimulus onset; it activated a buzzer for $0.5 \mathrm{sec}$ and initiated a 10-sec time-out period, after which the trial was repeated (correction trial).

During the training period, the stimuli were alternated every day; only one stimulus was presented for all trials in a session, and only one response was correct. During the next day, the other stimulus was presented on all trials. This procedure ensured that the rat received training to both stimuli and both responses

During Days 6-21, variable delays were interposed between the start of a trial and the presentation of the stimulus in order to reduce the rat's ability to predict the onset of the stimulus. The delay was initially $0.5 \mathrm{sec}$ and gradually increased in duration and variability in the following progression: $1 \mathrm{sec} ; 1$ and $2 \mathrm{sec} ; 1,2$, and $3 \mathrm{sec}$. Stimuli continued to alternate every day.

A variable reward schedule was used throughout the experiment to provide more reinforcement for fast correct responses than for slow correct responses. The reinforcement window was the length of time following a stimulus during which a correct response would produce reinforcement. At the start of training, the reinforcement window was $10 \mathrm{sec}$; it was gradually reduced to $1 \mathrm{sec}$ during the training period. The reinforcement window was divided into four equal periods. Correct responses in each successive period produced decreasing amounts of water: $0.04,0.03,0.02$, and $0.01 \mathrm{ml}$. A correct $\mathrm{RT}$ exceeding the reinforcement window was not reinforced.

\section{Testing}

All data reported in this paper were collected during the testing phase that followed the training phase. Procedures were similar to those described for the final training sessions. A trial began when the rat pressed both levers simultaneously. After a variable delay of 1,2 , or $3 \mathrm{sec}$, a single stimulus, either a tone or a light, was presented. (One rat was tested with variable delays of 3,4 , or 5 sec.) Correct, incorrect, and premature responses were treated in the same manner as those during the training sessions.

One test session, 45-60 min long, was given each day and consisted of 100-200 trials. The relative frequency of the two stimuli remained constant within a session, but changed from session to session. Five frequency pairs (frequency of tone/frequency of light, expressed as percentages) were presented in the following order, with the $50 / 50$ condition presented twice: $0 / 100,10 / 90,50 / 50$, $100 / 0,90 / 10,50 / 50$. This series was repeated in the same order throughout the study.

\section{Data Analysis}

The data from the first 20 trials in a session were discarded. These trials served as a warm-up and provided information to the rat regarding the relative stimulus frequencies for that session.

For the analysis of general session effect of stimulus frequency, mean RTs for correct responses and percentage of errors were calculated for each type of stimulus and each stimulus frequency using data accumulated from noncorrection trials. For analysis of stimulus probability and repetition effects, each trial was categorized by the stimulus presented on prior trials. Trials in which the stimulus changed from the previous trial were labeled a-repetition trials. Trials following one, two, or three trials of the same stimulus were designated 1-, 2-, or 3-repetition trials, respectively. Stimulus probability effects were assessed using data from all choice conditions $(10 \%, 50 \%, 90 \%)$. (The $100 \%$ condition was excluded because no choice was involved.) Only 0 - and 1 -repetition trials were included in this analysis, because the $10 \%$ stimulus probability condition produced few examples of 2-and 3-repetition trials. Stimulus repetition effects were assessed using data from 0-, 1-, 2-, and 3-repetition trials in the $50 \%$ and $90 \%$ conditions.
Discriminability $(D)$ and response bias (or response criterion, c) provide additional measures with which to compare the psychological mechanisms of expectancy in rats and humans. Both discriminability and response bias were calculated for all choice conditions (tone/light): $90 / 10,50 / 50,10 / 90$. Discriminability, a measure of the ease with which the stimuli can be differentiated from each other, was calculated using the following equation, derived from Luce's choice theory (Estes, 1982; Luce, 1963):

$$
D=\ln \frac{(100-\text { visual errors }) \times(100-\text { auditory errors })}{\text { (visual errors } \times \text { auditory errors })}
$$

where visual and auditory errors are expressed as percentages. Discriminability equal to zero indicates total confusion between the two stimuli; larger values of $D$ indicate better discriminability between the two stimuli. Response bias, a measure of the tendency to respond as if a particular stimulus had been presented, was calculated using the following equation (Estes, 1982; Luce, 1963):

$$
c=0.5 \times \ln \frac{(100-\text { visual errors }) \times \text { auditory errors }}{(100-\text { auditory errors }) \times \text { visual errors }} .
$$

Positive values of $c$ indicate a tendency to respond as if the light had been presented. Negative values of $c$ indicate a tendency to respond as if the tone had been presented.

Within each stimulus type and relative frequency, the data from each delay were pooled and analyzed together. For each rat, mean RTs for correct responses, errors, discriminability, and response criterion were calculated for each stimulus frequency using mean session values. Mean values across all sessions with the same stimulus frequency were used in all analyses and statistical comparisons (reported in the Results section). Responses less than $100 \mathrm{msec}$ or greater than $1 \mathrm{sec}$ were considered fast guesses or misses, respectively, and these trials were excluded from all analyses. In addition, incorrect responses were excluded from the RT analysis.

Statistical analysis was performed using an analysis of variance (ANOVA) with a repeated measures design. Post hoc analyses of the stimulus frequency conditions that contributed to the session effect were performed using the Newman-Keuls multiple range test, with critical differences calculated at the $p<.05$ level.

\section{Results}

\section{General Session Effects of Stimulus Frequency}

Reaction time. Mean RT decreased as the relative stimulus frequency increased $[F(3,15)=9.27, p<.001$; see Table 1]. In addition, mean RT to an auditory stimulus (auditory RT) was reliably faster than RT to a visual stimulus (visual RT) $[F(1,5)=14.55, p<.05]$. Stimulus type and stimulus frequency interacted significantly, indicating a greater effect of stimulus frequency on visual $\mathrm{RT}$ than on auditory $\mathrm{RT}[F(3,15)=5.76, p<.01]$.

Because previous studies demonstrated that attention is captured differently by stimuli in the visual and auditory modalities, separate analyses were conducted for responses to visual and auditory stimuli. Visual RT decreased as the relative frequency of a visual stimulus increased $[F(3,15)=11.96, p<.001]$. Visual RTs in the $100 \%$ and $90 \%$ conditions were reliably faster than those in the $50 \%$ and $10 \%$ conditions (within-group error, $\left.M S_{e}=559, p<.05\right)$. The effect of stimulus frequency on auditory RT approached significance $[F(3,15)=2.75$, $p=.08]$.

Errors. The mean rate of errors decreased as the stimulus frequency increased $[F(3,15)=10.47, p<.001$; see Table 1]. The percentage of visual and auditory er- 
Table 1

Mean RTs (in Milliseconds) and Mean Percentages of Errors to Tone and Light for Rats and Humans Arranged by Stimulus Frequency

\begin{tabular}{|c|c|c|c|c|c|c|c|c|}
\hline \multirow{3}{*}{$\begin{array}{c}\text { Stimulus } \\
\text { Frequency } \\
\text { (\%) }\end{array}$} & \multicolumn{4}{|c|}{ Experiment 1: Rats } & \multicolumn{4}{|c|}{ Experiment 2: Humans } \\
\hline & \multicolumn{2}{|c|}{ RTs } & \multicolumn{2}{|c|}{ Errors } & \multicolumn{2}{|c|}{ RTs } & \multicolumn{2}{|c|}{ Errors } \\
\hline & Tone & Light & Tone & Light & Tone & Light & Tone & Light \\
\hline 10 & 285 & 384 & 13.8 & 11.7 & 356 & 394 & 22.0 & 26.3 \\
\hline 50 & 256 & 366 & 9.3 & 7.3 & 293 & 389 & 5.3 & 8.3 \\
\hline 90 & 253 & 328 & 5.3 & 3.2 & 242 & 329 & 1.0 & 1.3 \\
\hline 100 & 263 & 311 & 3.3 & 1.7 & 217 & 289 & 2.0 & 1.0 \\
\hline
\end{tabular}

rors were similar $[F(1,5)<1]$. Stimulus type and frequency did not interact $[F(3,15)<1]$.

Visual errors decreased as the relative frequency of a visual stimulus increased $[F(3,15)=9.78, p<.005]$. Visual errors in the $50 \%, 90 \%$, and $100 \%$ conditions were reliably smaller than the visual errors in the $10 \%$ condition $\left(M S_{\mathrm{c}}=12, p<.05\right)$. Visual errors in the $100 \%$ condition were smaller than those in the $50 \%$ condition $\left(M S_{\mathrm{c}}=12, p<.05\right)$. Auditory errors decreased as the relative frequency of an auditory stimulus increased $[F(3,15)=6.23, p<.01$; see Table 1]. Auditory errors in the $90 \%$ and $100 \%$ conditions were reliably smaller than those in the $10 \%$ condition $\left(M S_{e}=16, p<.05\right)$.

Response bias and discriminability. Response bias shifted toward the response associated with the more frequent stimulus $[F(2,10)=27.82, p<.001$; see Figure 1]. Response bias differed reliably between each pair of conditions $\left(M S_{\mathrm{e}}=0.079, p<.05\right)$. The discriminability between the light and tone remained constant as stimulus frequency was varied $[F(2,10)=2.41$; see Figure 2].

\section{Effects of Stimulus Probability}

The effects of stimulus probability controlled for stimulus repetition were analyzed by comparing the $10 \%$, $50 \%$, and $90 \%$ conditions for both stimuli within the same level of repetition (i.e., 0 or 1 ).

Reaction time. Mean RT decreased significantly as stimulus probability increased $[F(2,10)=4.45, p<.05$; see Table 2]. Auditory RT was faster than visual RT $[F(1,5)=12.78, p<.05]$. Stimulus type and stimulus probability did not interact $[F(2,10)=1.4]$.

Visual, but not auditory, RT decreased as the stimulus probability increased [visual, $F(2,10)=7.13, p<.05$; auditory, $F(2,10)=1.56]$.

Errors. The mean rate of errors decreased significantly as stimulus probability increased $[F(2,10)=8.75, p<$ .01 ; see Table 3]. Visual and auditory errors were simi-

\section{Response Bias}

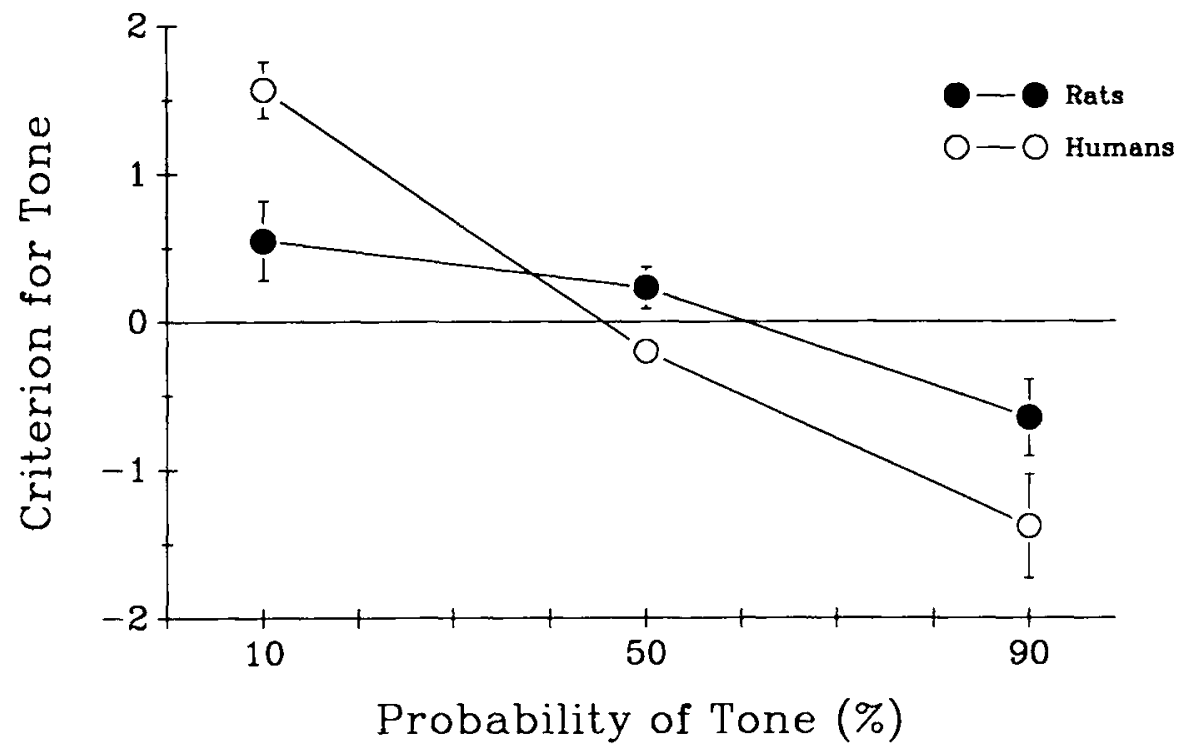

Figure 1. Response bias for rats and humans as a function of stimulus frequency. Positive bias values indicate a tendency to respond as if the light had been presented. Negative bias values indicate a tendency to respond as if the tone had been presented. 


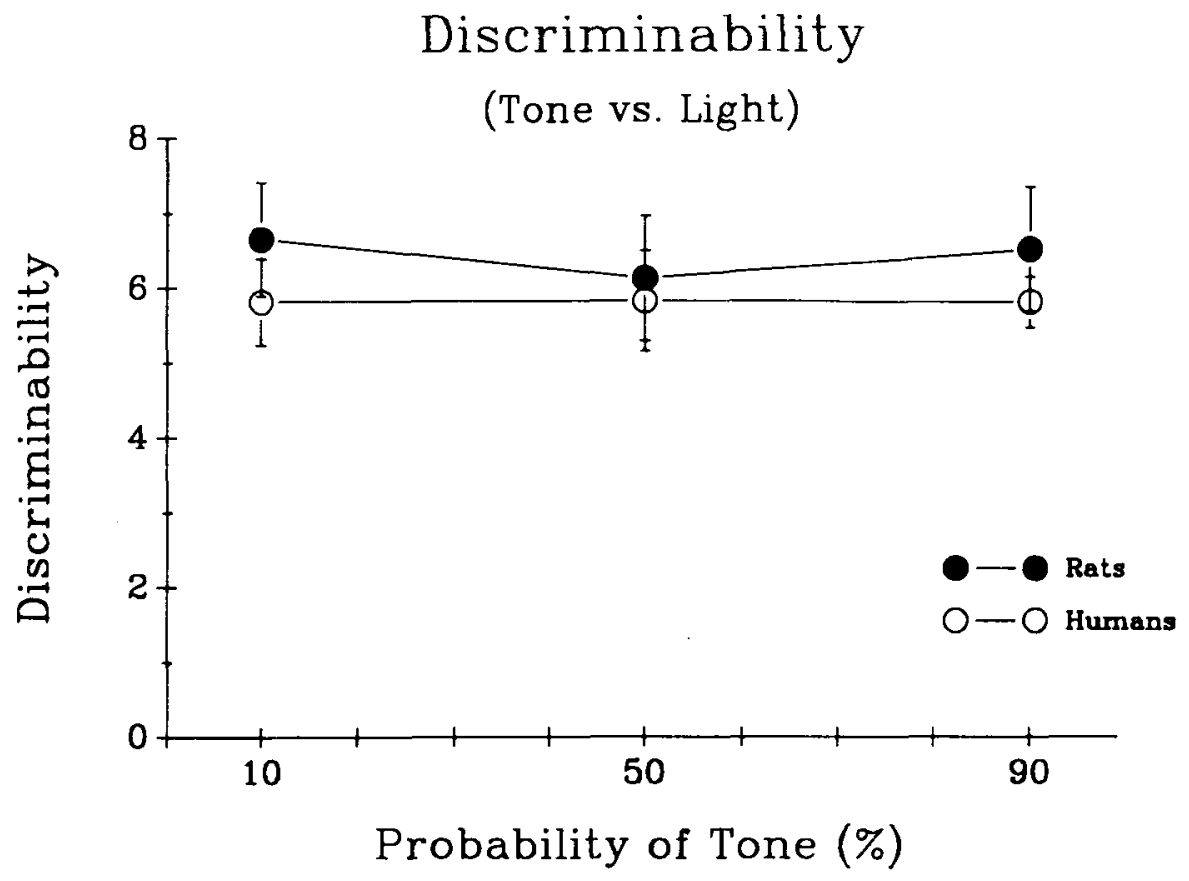

Figure 2. Discriminability for rats and humans as a function of stimulus frequency. A value of $O$ indicates no discriminability between the light and tone. Langer values indicate better discriminability between the two stimuli.

$\operatorname{lar}[F(1,5)<1]$. Stimulus type and stimulus probability did not interact $[F(2,10)<1]$.

Both visual and auditory errors decreased as the stimulus probability increased [visual, $F(2,10)=4.93, p<$ .05 ; auditory, $F(2,10)=6.64, p<.05]$.

\section{Effects of Stimulus Repetition}

The effects of stimulus repetition controlled for stimulus probability were investigated by comparing the $0-, 1-$, 2-, and 3-repetition trials for both stimuli within the same probability condition (i.e., $50 \%$ or $90 \%$ ).

Reaction time. Stimulus repetition had a significant influence on RT $[F(3,15)=5.00, p<.05$; see Table 2]. Auditory RT was also faster than visual RT $[F(1,5)=$

Table 2

Mean RTs (in Milliseconds) to Tone and Light for Rats and Humans Arranged by the Number of Stimulus Repetitions and Stimulus Probability

\begin{tabular}{|c|c|c|c|c|c|c|}
\hline \multirow{2}{*}{$\begin{array}{l}\text { Number of } \\
\text { Stimulus } \\
\text { Repetitions }\end{array}$} & \multicolumn{3}{|c|}{ Tone } & \multicolumn{3}{|c|}{ Light } \\
\hline & $10 \%$ & $50 \%$ & $90 \%$ & $10 \%$ & $50 \%$ & $90 \%$ \\
\hline \multicolumn{7}{|c|}{ Experiment 1: Rats } \\
\hline $\begin{array}{l}0 \\
1 \\
2 \\
3\end{array}$ & $\begin{array}{l}285 \\
287\end{array}$ & $\begin{array}{l}261 \\
259 \\
259 \\
253\end{array}$ & $\begin{array}{l}271 \\
255 \\
253 \\
251\end{array}$ & $\begin{array}{l}381 \\
355\end{array}$ & $\begin{array}{l}375 \\
354 \\
357 \\
355\end{array}$ & $\begin{array}{l}345 \\
330 \\
324 \\
319\end{array}$ \\
\hline \multicolumn{7}{|c|}{ Experiment 2: Humans } \\
\hline $\begin{array}{l}0 \\
1 \\
2 \\
3\end{array}$ & $\begin{array}{l}331 \\
349\end{array}$ & $\begin{array}{l}312 \\
286 \\
263 \\
256\end{array}$ & $\begin{array}{l}280 \\
259 \\
237 \\
239\end{array}$ & $\begin{array}{l}383 \\
358\end{array}$ & $\begin{array}{l}393 \\
394 \\
369 \\
373\end{array}$ & $\begin{array}{l}359 \\
349 \\
343 \\
332\end{array}$ \\
\hline
\end{tabular}

13.03, $p<.05]$. Stimulus type and stimulus repetition did not interact $[F(3,15)<1]$.

Visual, but not auditory, RT reliably decreased as the number of stimulus repetitions increased [visual, $F(3,15)$ $=3.17, p=.05$; auditory, $F(3,15)=1.17]$.

Errors. The rate of errors significantly decreased as stimulus repetition increased $[F(3,15)=13.55, p<$ .001 ; see Table 3]. Auditory and visual errors were similar $[F(1,5)<1]$. Stimulus type and stimulus repetition did not interact $[F(3,15)=1.63]$.

Both visual and auditory errors decreased as the number of stimulus repetitions increased [visual, $F(3,15)=$ $9.19, p<.005$; auditory, $F(3,15)=3.94, p<.05]$. For visual errors, stimulus repetition interacted with stimu-

Table 3

Mean Error Rate (\%) to Tone and Light for Rats and Humans Arranged by the Number of Stimulus Repetitions and Stimulus Probability

\begin{tabular}{|c|c|c|c|c|c|c|}
\hline \multirow{2}{*}{$\begin{array}{l}\text { Number of } \\
\text { Stimulus } \\
\text { Repetitions }\end{array}$} & \multicolumn{3}{|c|}{ Tone } & \multicolumn{3}{|c|}{ Light } \\
\hline & $10 \%$ & $50 \%$ & $90 \%$ & $10 \%$ & $50 \%$ & $90 \%$ \\
\hline \multicolumn{7}{|c|}{ Experiment 1: Rats } \\
\hline $\begin{array}{l}0 \\
1 \\
2 \\
3\end{array}$ & $\begin{array}{l}15.8 \\
16.4\end{array}$ & $\begin{array}{r}11.1 \\
10.3 \\
8.0 \\
7.6\end{array}$ & $\begin{array}{l}7.5 \\
7.3 \\
4.6 \\
7.2\end{array}$ & $\begin{array}{r}15.3 \\
7.7\end{array}$ & $\begin{array}{r}12.3 \\
7.6 \\
5.7 \\
4.4\end{array}$ & $\begin{array}{l}5.4 \\
4.5 \\
4.4 \\
3.5\end{array}$ \\
\hline \multicolumn{7}{|c|}{ Experiment 2: Humans } \\
\hline $\begin{array}{l}0 \\
1 \\
2 \\
3\end{array}$ & $\begin{array}{l}23.1 \\
13.4\end{array}$ & $\begin{array}{l}9.2 \\
4.3 \\
1.2 \\
1.7\end{array}$ & $\begin{array}{l}3.9 \\
1.9 \\
0.8 \\
0.5\end{array}$ & $\begin{array}{l}26.4 \\
18.8\end{array}$ & $\begin{array}{r}10.2 \\
8.8 \\
5.5 \\
4.8\end{array}$ & $\begin{array}{l}5.5 \\
2.0 \\
2.3 \\
1.3\end{array}$ \\
\hline
\end{tabular}


lus frequency, indicating a greater effect of stimulus repetition in the $50 \%$ condition than in the $90 \%$ condition $[F(3,15)=4.47, p<.05]$.

\section{Discussion}

Expectancy, as manipulated by the relative frequency of an auditory or visual stimulus, altered response bias. As the visual stimulus became more frequent, the tendency to respond with the left lever increased. As the auditory stimulus became more frequent, the tendency to respond with the right lever increased. Discriminability between the visual and auditory stimuli did not change as the stimulus frequency was manipulated.

Visual RT and visual errors changed as a function of the stimulus frequency. Both RT and errors decreased as the frequency of the visual stimulus increased, demonstrating significant general session effects. The general session effects of stimulus frequency were due to changes in both stimulus probability and stimulus repetition. In the analyses that separated the effects of stimulus probability from those of stimulus repetition, visual RT and errors decreased as the stimulus probability or stimulus repetition increased. In pigeons, responses are faster and/or more accurate to frequent stimuli than to infrequent stimuli (Blough, 1989). Likewise, responses in human subjects are influenced by both stimulus probability and stimulus repetition (Hick, 1952; Hyman, 1953; Kornblum, 1973). This overall pattern of results for visual RT and errors may be generated by a reduction in response criterion as the stimulus frequency is increased (Fitts, 1966).

Auditory errors, but not auditory RT, varied with relative stimulus frequency. As the frequency of an auditory stimulus increased, errors decreased and RT remained constant. The general session effect of stimulus frequency for auditory errors was due to changes in both stimulus probability and stimulus repetition. Auditory errors decreased as stimulus probability or stimulus repetition increased.

Similar analyses of auditory RT revealed that stimulus probability and stimulus repetition had little influence on RT, although the general session effects of stimulus frequency approached significance. The lack of a general session effect of stimulus frequency for auditory RT might have occurred because auditory RT was so fast that the effects of stimulus frequency were reduced. Another possibility is that the auditory stimulus might have been more salient than the visual stimulus. If the auditory stimulus were loud, it might automatically capture attention, as proposed for humans and rats (Meck, 1984; Posner, Nissen, \& Klein, 1976). The automaticity might have been due to the extensive training of our subjects, because auditory RT decreases to a greater extent than visual RT following long-term training in humans (Steinbach, von Dreden, \& Poppel, 1991), possibly due to differential rates of acquiring automaticity in the auditory and visual systems.

The significant interaction between stimulus frequency and stimulus type for RT provides additional evidence that expectancy and/or attention is different for visual and auditory stimuli. Stimulus frequency and stimulus type, however, did not interact for errors. This difference between RT and errors may be accounted for by a speed-accuracy shift.

In summary, expectancy shifted response bias to the more frequent stimulus, but it did not alter discriminability. Auditory errors, visual errors, and visual RT decreased as stimulus probability or the number of stimulus repetitions increased.

\section{EXPERIMENT 2: HUMANS}

Experiment 2 measured the effects of relative stimulus frequency in humans using the same procedures as those used for rats in Experiment 1. If similar cognitive processes underlie expectancy in rats and humans, performance should vary as a function of stimulus frequency in both species. As stimulus frequency increases, RTs and errors should decrease, response bias should shift toward the more frequent stimulus, and discriminability should remain constant. With repetition of a stimulus, RTs and errors should also decrease.

\section{Method}

The methods were the same as those in Experiment 1, except as noted below.

\section{Subjects}

Four subjects -3 female employees of the Johns Hopkins University and 1 author (F.M.)-participated in Experiment 2. All subjects had normal or corrected-to-normal vision and normal hearing. Three of the 4 subjects were right-handed.

\section{Test Apparatus}

An IBM PC-AT-compatible computer controlled the experiment and recorded the data. The internal computer clock measured RT and delay intervals with $1-$ msec resolution. A homemade response box had two push-button switches located $4 \mathrm{~cm}$ apart. The response box was connected to the computer game port.

A color monitor (Princeton Graphics SR-12) with a Sigma-400 graphics card (Sigma Designs) displayed the visual stimulus, a filled light gray rectangle $(8 \mathrm{~cm}$ high $\times 12 \mathrm{~cm}$ wide) in the center of the monitor screen. The rectangle subtended an angle of $11.3^{\circ} \times 16.7^{\circ}$ from a typical viewing distance of $40 \mathrm{~cm}$; its luminance was $136 \mathrm{~cd} / \mathrm{m}^{2}$. The luminance of the remainder of the screen was $0.22 \mathrm{~cd} / \mathrm{m}^{2}$.

The internal computer speaker delivered the auditory stimulus and the negative secondary reinforcer (NSR). The auditory stimulus was a 3-kHz tone with a peak amplitude of $80 \mathrm{~dB}$. The NSR was a $500-\mathrm{Hz}$ tone with a peak amplitude of $55 \mathrm{~dB}$.

\section{Training}

Each subject was comfortably seated directly in front of the monitor, speaker, and response box in an isolated, enclosed room. The right and left index fingers of the subject rested on the right and left switches, respectively, of the response box. Each trial was initiated by pressing both buttons simultaneously. A stimulus was presented following a random interval of 1,2 , or $3 \mathrm{sec}$. As with the rats, the correct response was a release of the left button for the visual stimulus and a release of the right button for the auditory stimulus. Following a correct response, the stimulus was turned off and an intertrial interval of $0.5 \mathrm{sec}$ began. Following an incor- 
rect response, the stimulus was turned off, the NSR was activated for $1 \mathrm{sec}$, and a delay of $5 \mathrm{sec}$ was initiated. Following a premature response, the NSR was activated for $0.5 \mathrm{sec}$ and a delay of $5 \mathrm{sec}$ was initiated. An intertrial interval of $0.5 \mathrm{sec}$ followed the delays associated with the incorrect and premature responses.

Each subject had one practice session. The subjects were told to respond accurately to the stimuli and as rapidly as possible. The practice session consisted of six blocks of trials (50 trials each); each block used one of five stimulus frequency pairs (frequency of tone/frequency of light, expressed as percentages) in the following order, with the $50 / 50$ condition presented twice: $0 / 100,10 / 90$, $50 / 50,100 / 0,90 / 10,50 / 50$.

\section{Testing}

One test session was given each day, with 250 trials per session; each session had a single frequency condition. A total of 18 sessions ( 3 sessions at each stimulus frequency except the $50 / 50$ condition, which had 6 sessions) was given to each subject. No breaks were required within a session, but each subject was encouraged to rest as long as desired between trials. Each test session lasted about $\mathbf{1 5} \mathrm{min}$. Only data from the test sessions are reported in this paper. As in Experiment 1, data from the first 20 trials in a session were discarded.

\section{Results}

\section{General Session Effects of Stimulus Frequency}

Reaction time. Mean RT decreased as the relative stimulus frequency increased $[F(3,9)=95.52, p<.001$; see Table 1]. Auditory RT was also faster than visual RT $[F(1,3)=77.40, p<.005]$. The interaction of stimulus type and stimulus frequency approached significance $[F(3,9)=2.92, p=.09]$.

As in Experiment 1, visual and auditory responses were analyzed separately because previous studies demonstrated that auditory stimuli can capture attention more readily than can visual stimuli. Visual RT decreased as the relative frequency of a visual stimulus increased $[F(3,9)=$ $25.65, p<.001]$. Visual RT at each frequency was significantly different from that at every other frequency, except the $50 \%$ and $10 \%$ conditions did not differ $\left(M S_{\mathrm{e}}\right.$ $=395, p<.05$ ). Auditory RT decreased as the relative frequency of an auditory stimulus increased $[F(3,9)=$ $47.98, p<.001]$. Each auditory RT was different from every other RT, except that the $100 \%$ and $90 \%$ conditions did not differ $\left(M S_{\mathrm{e}}=316, p<.05\right)$.

Errors. The mean rate of errors decreased as the relative stimulus frequency increased $[F(3,9)=12.50, p<$ .001 ; see Table 1]. Visual and auditory errors were similar $[F(1,3)=1.74]$. Stimulus type and stimulus frequency did not interact $[F(3,9)<1]$.

$V$ isual errors decreased as the relative frequency of a visual stimulus increased $[F(3,9)=7.63, p<.01]$. Visual errors in the $100 \%, 90 \%$, and $50 \%$ conditions were reliably smaller than those in the $10 \%$ condition $\left(M S_{\mathrm{e}}=\right.$ $73, p<.05$ ). Auditory errors decreased as the relative frequency of an auditory stimulus increased $[F(3,9)=$ $23.65, p<.001]$. Auditory errors in the $100 \%, 90 \%$, and $50 \%$ conditions were smaller than those in the $10 \%$ condition $\left(M S_{\mathrm{c}}=16, p<.05\right)$.

Response bias and discriminability. Response bias shifted toward the more frequent stimulus $[F(2,6)=$
48.34, $p<.001$; see Figure 1]. Response bias reliably differed among all conditions $\left(M S_{\mathrm{e}}=0.212, p<.05\right)$. Discriminability between the light and tone remained constant as the relative stimulus frequency was varied $[F(2,6)<1$; Figure 2].

\section{Effects of Stimulus Probability}

To separate the effects of stimulus probability and stimulus repetition, each factor (probability or repetition) was analyzed while the other factor was held constant. This analysis was identical to that described in Experiment 1.

Reaction time. Stimulus probability, independent of stimulus repetition, significantly influenced $\operatorname{RT}[F(2,6)=$ $5.97, p<.05$; see Table 2]. Auditory RT was also faster than visual RT $[F(1,3)=41.70, p<.01]$. The interaction of stimulus type and stimulus probability approached significance $[F(2,6)=3.97, p=.08]$.

Auditory RT decreased as stimulus probability increased, but visual RT did not [auditory, $F(2,6)=7.83$, $p<.05$; visual, $F(2,6)=2.39$ ].

Errors. The mean error rate decreased significantly as stimulus probability increased $[F(2,6)=11.68, p<.01$; see Table 3]. Auditory and visual errors were not statistically different $[F(1,3)=6.37, p=.09]$. Stimulus type and stimulus probability did not interact $[F(2,6)<1]$.

Both auditory and visual errors decreased as the stimulus probability increased [visual, $F(2,6)=9.01, p<$ .05 ; auditory, $F(2,6)=9.85, p<.05]$. For auditory errors, stimulus probability interacted with stimulus repetition, indicating a greater effect of stimulus probability for 0-repetition trials than for 1-repetition trials $[F(2,6)=$ $14.02, p<.01]$.

\section{Effects of Stimulus Repetition}

Reaction time. Stimulus repetition, independent of stimulus probability, influenced RT $[F(3,9)=16.47$, $p<.001$; see Table 2]. Auditory RT was also significantly faster than visual $\mathrm{RT}[F(1,3)=79.07, p<.005]$. The interaction of stimulus type and stimulus repetition approached significance $[F(3,9)=3.31, p=.07]$.

Auditory RT decreased as stimulus repetitions increased, but visual RT did not, although the effect for visual RT approached significance [auditory, $F(3,9)=$ $27.61, p<.001$; visual, $F(3,9)=3.58, p=.06]$.

Errors. The mean rate of errors decreased reliably as stimulus repetition increased $[F(3,9)=11.27, p<.005$; see Table 3]. Visual errors were also greater than auditory errors $[F(1,3)=61.76, p<.005]$. Stimulus type and stimulus repetition did not interact $[F(3,9)<1]$.

Auditory errors decreased as the number of stimulus repetitions increased $[F(3,9)=27.59, p<.001]$. The effect for visual errors approached significance $[F(3,9)=$ $3.45, p=.07]$.

\section{Discussion}

Expectancy altered response bias, shifting it toward the response associated with the more frequent stimulus. Discriminability between the visual and auditory stimuli re- 
mained unchanged as stimulus probability was altered. Mean RT and errors for both stimuli decreased as the relative frequency of the stimuli increased. Thus, RTs and errors for both stimuli exhibited general session effects of stimulus frequency. Further analysis was done to separate probability effects from repetition effects.

Auditory RT and auditory errors were sensitive to both stimulus probability and stimulus repetition. Auditory RTs and errors decreased as stimulus probability or stimulus repetition increased. Thus, both stimulus probability and stimulus repetition contributed to the session effect observed for auditory RTs and errors.

Although visual RTs in humans decreased as stimulus frequency increased, neither the effect of stimulus probability nor that of stimulus repetition reached significance. For visual errors, the effect of stimulus probability, but not repetition, reached significance. The failure to reach significance is most likely due to the small number of subjects in our study, because both probability and repetition effects for responses to visual stimuli have previously been observed in humans (Hick, 1952; Hyman, 1953; Kornblum, 1973). These data suggest that, like auditory RTs and errors, both stimulus probability and stimulus repetition can contribute to the general session effects of stimulus frequency for visual RTs and errors.

The interaction between stimulus type and stimulus frequency approached significance for RTs, suggesting that expectancy and/or attention for visual and auditory stimuli is different. This finding is similar to those previously reported for humans and rats (Meck, 1984; Posner, Nissen, \& Klein, 1976).

These results are in accordance with a long history of studies in human subjects (Hick, 1952; Hyman, 1953; Komblum, 1973; Merkel, 1885; Pew, 1969). However, this experiment was necessary to measure the magnitude of the general session effect of stimulus frequency and the specific effects of stimulus probability and stimulus repetition in humans using a set of procedures similar to those used for rats.

\section{GENERAL DISCUSSION}

In rats and humans, the general session effects of stimulus frequency were similar. Both species shifted response bias toward the more frequent stimulus but did not alter stimulus discriminability. The shift in response bias was associated with a decreased RT to the more frequent stimulus in the visual modality. Similar results have been obtained for pigeons (Blough, 1989). This pattern of results demonstrates that the frequency of previous events affects expectancy in a number of species, including rats and humans.

In both rats and humans, RTs and errors were influenced by stimulus probability and stimulus repetition. Visual RTs, visual errors, and auditory errors in rats decreased as stimulus probability or stimulus repetition increased. Auditory RTs and auditory errors in humans showed the same pattern; both decreased as stimulus prob- ability or stimulus repetition increased. Visual errors decreased as the stimulus probability increased. The effects of stimulus probability and repetition approached significance for visual RTs. These results confirm that RTs and errors in human subjects depend on both stimulus probability and repetition and extend these findings to rats.

One difference in the performance of rats and humans was the pattern of RTs for the auditory stimulus. In humans, auditory RTs decreased as the stimulus probability or stimulus repetition increased. In rats, auditory RTs were constant for all stimulus probabilities and repetitions. The differences observed for the visual and auditory RTs are analogous to those obtained in a temporal discrimination task (Meck, 1984). Rats, trained to discriminate between different stimulus durations, had expectancy directed to either the auditory or the visual modality by the use of stimulus frequencies or cues. Under conditions that favored expectancy for the auditory modality, initiation of timing was delayed when a visual stimulus was presented, indicating a delay in switching attention from the auditory to the visual modality. In contrast, under conditions favoring expectancy for the visual modality, initiation of timing was not delayed when an auditory stimulus was presented, suggesting that the switching of attention from the visual to auditory modality occurs without a significant time delay. The insensitivity of the auditory RTs in rats to manipulations of expectancy might $\alpha$ cur for a variety of reasons, and the present experiment was not designed to distinguish among these. Auditory stimuli may more readily capture attention than visual ones (Posner, Nissen, \& Klein, 1976), at least with presentation parameters used here. Alternatively, the effects of stimulus frequency may be reduced because the auditory RTs were so fast. Although mean RT was constant at all stimulus frequencies, more errors occurred for infrequent tones than for frequent ones, suggesting a speed-accuracy tradeoff. Additional experiments can assess these and other factors.

The similar results from rats and humans support the conclusion that rats can provide a useful model of human performance in expectancy tasks. Although further work is required to extend the rat model, this conclusion justifies the use of rats in neurobiological research into the neural mechanisms of probability and repetition effects. Additional comparative studies can generate and validate new tasks to model other cognitive processes, such as attention.

Finally, the present experiment introduces an experimental procedure to measure two-choice RTs and accuracy in rats. Although experiments have measured RTs of a single response in rats (Gallagher \& Burwell, 1989; MacRae, Spirduso, \& Wilcox, 1988; Mittleman, Whishaw, \& Robbins, 1988), this procedure is the first that allows measurement of RTs for two independent responses in rats. Because this type of procedure is so widely used in studies of human attentional processes, the development of an analogous procedure for animals can provide the opportunity to answer important questions about the cog- 
nitive and neural mechanisms involved in different types of attention.

\section{REFERENCES}

Bertelson, P. (1961). Sequential redundancy and speed in a serial twochoice responding task. Quarterly Journal of Experimental Psychology, 13, 90-102.

Bertelson, P. (1965). Serial choice reaction-time as a function of re sponse versus signal-and-response repetition. Nature, 206, 217-218.

Biederman, I., Stacy, E. W. (1974). Stimulus probability and stimulus set size in memory scanning. Journal of Experimental Psychology, 102, 1100-1107.

Biederman, I. \& ZACHARY, R. A. (1970). Stimulus versus response probability effects in choice reaction time. Perception \& Psychophysics, 7, 189-192.

Blackman, A. R. (1972). Stimulus probability and choice reaction time Perception \& Psychophysics, 12, 146-150.

Blovgh, P. M. (1989). Attentional priming and visual search in pigeons. Joumal of Experimental Psychology: Animal Behavior Processes, 15, 358-365.

Broadbent, D. E. (1958). Perception and communication. London: Pergamon.

Corbetta, M., Miezin, F. M., Dobmeyer, S., Shulman, G. L., \& Petersen, S. E. (1990). Attentional modulation of neural processing of shape, color, and velocity in humans. Science, 248, 1556-1559.

Deutsch, J. A., Deutsch, D. (1963). Attention: Some theoretical considerations. Psychological Review, 70, 80-90.

Dillon, P. J. (1966). Stimulus versus response decisions as determinants of the relative frequency effect in disjunctive reaction-time performance. Jourmal of Experimental Psychology, 71, 321-330.

Donchin, E., Karis, D., Bashore, T. R., Coles, M. G. H., \& GratTON, G. (1986). Cognitive psychophysiology and human information processing. In M. G. H. Coles, E. Donchin, \& S. W. Porges (Eds.), Psychophysiology systems, processes, and applications (pp. 244-267). New York: Guilford.

Duncan-Johnson, C. C., \&onchin, E. (1982). The P300 component of the event-related brain potential as an index of information processing. Biological Psychology, 14, 1-52.

EGETH, H. (1967). Selective attention. Psychological Bulletin, 67, 41-57.

ELLS, J. G., GorTs, G. H. (1971). Serial reaction time as a function of the nature of repeated events. Jourmal of Experimental Psychology: Human Perception \& Peformance, 8, 234-242.

EsTES, W. K. (1982). Similarity-related channel interactions in visual processing. Joumal of Experimental Psychology: Human Perception \& Performance, 8, 353-382.

FITTs, P. M. (1966). Cognitive aspects of information processing: III. Set for speed versus accuracy. Joumal of Experimental Psychology, 71, 849-857.

GAllagher, M., BurWell, R. D. (1989). Relationship of age-related decline across several behavioral domains. Neurobiology of Aging, 10, 691-708.

HAwXINS, H. L., FRIEDIN, B. D. (1972). The relative frequency effects and S-R compatibility. Psychonomic Science, 28, 329-330.

HAwkINS, H. L., Hosking, K. (1969). Stimulus probability as a determinant of discrete choice reaction time. Journal of Experimental Psychology, 82, 435-440.

Hick, W. E. (1952). On the rate of gain of information. Quarterly Journal of Experimental Psychology, 4, 11-26.

Hilly ARD, S. A., \& KUTAS, M. (1983). Electrophysiology of cognitive processing. Annual Review of Psychology, 34, 33-61

HinRICHS, J. V., KRAINZ, P. L. (1970). Expectancy in choice reaction time: Anticipation of stimulus or response. Joumal of Experimental Psychology, 85, 330-334.

HymaN, R. (1953). Stimulus information as a determinant of reaction time. Joumal of Experimental Psychology, 45, 188-196.
Kornblum, S. (1973). Sequential effects in choice reaction time: A tutorial review. In S. Kornblum (Ed.), Attention and performance IV (pp. 259-288). New York: Academic Press.

LABerge, D., \& Tweedy, J. R. (1964). Presentation probability and choice time. Journal of Experimental Psychology, 68, 477-481.

Landauer, T. K. (1964). Recency and recall time. Psychonomic Science, 1, 365-366

LUCE, R. D. (1963). Detection and recognition. In R. D. Luce, R. R. Bush, \& E. Galanter (Eds.), Handbook of mathematical psychology (pp. 103-189). New York: Wiley.

MacRae, P. G., Spirduso, W. W., \&ilcox, R. E. (1988). Reaction time and nigrostriatal dopamine function: The effects of age and practice. Brain Research, 451, 139-146.

MECK, W. H. (1984). Attentional bias between modalities: Effect on the internal clock, memory, and decision stages used in animal time discrimination. Annals of the New York Academy of Sciences, 423, 528-541

MERKEL, J. (1885). Die zeitlichen Verhaltnisse der Willensthatigkeit. Philosophische Studieren, 2, 73-127.

Miller, J. O., PACHella, R. G. (1973). Locus of the stimulus probability effect. Journal of Experimental Psychology, 101, 227-231.

Miller, J. O., \& PACHella, R. G. (1976). Encoding processes in memory scanning tasks. Memory \& Cognition, 4, 501-506.

Mittleman, G., Whishaw, I. Q., \& Robiins, T. W. (1988). Cortical lateralization of function in rats in a visual reaction time task. Behavioral Brain Research, 31, 29-36.

Niemi, P., NAAtAnen, R. (1981). Foreperiod and simple reaction time. Psychological Bulletin. 12, 63-75.

PaChella, R. G., Miller, J. O. (1976). Stimulus probability and same-different classification. Perception \& Psychophysics, 19, 29-34.

Pew, R. W. (1969). The speed-accuracy operating characteristic. In W. G. Koster (Ed.), Atrention and performance II (pp. 16-26). Amsterdam: North Holland.

Posner, M. I. (1980). Orienting of attention. Quarterly Joumal of Experimental Psychology, 32, 3-25.

Posner, M. I. (1986). Chronometric explorations of mind. New York: Oxford University Press.

Posner, M. I., Nissen, M. J., Klein, R. M. (1976). Visual dominance: An information-processing account of its origins and significance. Psychological Review, 83, 157-171.

Posner, M. I., Walker, J. A., Friedrich, F. J., Rafal, R. D. (1984). Effects of parietal lobe injury on covert orienting of visual attention. Joumal of Neuroscience, 4, 1863-1874.

RABBITT, P. M. A. (1959). Effects of independent variations in stimulus and response probability. Nature, 183, 1212.

SANDERS, A. F. (1970). Some variables affecting the relation between relative stimulus frequency and choice reaction time. Acto Psychologica, 33, 45-55.

SмIтн, M. C. (1968). Repetition effect and short-term memory. Journal of Experimental Psychology, 77, 435-439.

Steinbach, T., von Dreden, G., Poppel, E. (1991). Long-term training in a choice reaction time task reveals different leaming characteristics for the visual and auditory system. Naturwissenschaften, 78 , 185-187.

Theios, J. (1973). Reaction time measurements in the study of memory processes: Theory and data. In G. H. Bower (Ed.), Psychology of learning and motivation: Advances in research and theory (Vol. 7, pp. 43-85). New York: Academic Press.

THEIOs, J. (1975). The components of response latency in simple human information processing tasks. In P. M. A. Rabbitt \& S. Domic (Eds.), Attention and performance V (pp. 418-440). London: Academic Press.

(Manuscript received February 13, 1991; revision accepted for publication January 8,1992 .) 